12

\title{
Времяпролетная нейтронография нанокристаллических порошков нестехиометрического карбида ниобия $\mathrm{NbC}_{0.77}$
}

\author{
() А.С. Курлов ${ }^{1}$, А.И. Гусев ${ }^{1,}$, В.С. Кузнецов ${ }^{2}$, И.А. Бобриков ${ }^{2}$, А.М. Балагуров ${ }^{2}$, А.А. Ремпель ${ }^{1}$ \\ ${ }^{1}$ Институт химии твердого тела УрО РАН, \\ Екатеринбург, Россия \\ ${ }^{2}$ Объединенный институт ядерных исследований, \\ Дубна, Россия \\ ฯ E-mail: gusev@ihim.uran.ru
}

(Поступила в Редакцию 3 августа 2016 г.)

\begin{abstract}
Методом дифракции нейтронов изучена эволюция микроструктуры порошков нестехиометрического карбида ниобия $\mathrm{NbC}_{0.77}$, подвергнутых высокоэнергетическому размолу. Установлено, что полученные размолом нанокристаллические порошки имеют микронеоднородное строение и в них можно четко идентифицировать две фракции, отличающиеся размером частиц. Одна фракция имеет размер частиц менее $60 \mathrm{~nm}$, размер частиц второй фракции более $250 \mathrm{~nm}$. Оценены средний размер областей когерентного рассеяния и величина микронапряжений в нанокристаллитах, учитывающая анизотропию деформационных искажений.
\end{abstract}

DOI: 10.21883/FTT.2017.03.44175.320

\section{1. Введение}

В последние десятилетия в физическом материаловедении развиваются методы получения веществ и материалов в нанокристаллическом состоянии. Это связано с модификацией свойств твердых веществ при уменьшении размера кристаллитов (зерен, частиц) до 20-30 nm и менее [1-3]. Механический размол (ball milling) простой, эффективный и производительный способ получения различных нанокристаллических порошков [3-7].

Дифракция коротковолнового излучения (рентгеновского или нейтронного) - один из основных методов изучения размера частиц и микродеформаций (microstrains) в нанокристаллических веществах, информацию о которых можно получить, анализируя ширину и форму профиля дифракционных отражений. Из нейтронных инструментов наиболее перспективными для таких исследований являются дифрактометры по времени пролета (time-of-flight (TOF)) на импульсных источниках нейтронов. Использование сплошного по длине волны спектра нейтронов позволяет охватить очень широкий интервал межплоскостных расстояний $d_{h k l}$ (от $\sim 0.05$ до $\sim 1.5 \mathrm{~nm}$ и более), внутри которого разрешающая способность ТОF-дифрактометра очень слабо зависит от $d_{h k l}$, но улучшается с ростом $d$. Эти факторы позволяют более точно, чем на стандартном дифрактометpe с монохроматическим пучком нейтронов, оценивать влияние различных дефектов кристалла на профиль и ширину отражений.

Пионерские исследования влияния нестехиометрии и малого размера частиц на особенности микроструктуры нанокристаллических веществ методом TOFнейтронографии появились только в 2014-2016 годах [8-11].

В данной работе методом времяпролетной нейтронной дифрактометрии экспериментально изуче- на микроструктура нестехиометрического кубического (пр. гр. $F m \overline{3} m)$ карбида ниобия $\mathrm{NbC}_{0.77}$, в котором при $T \geq 900 \mathrm{~K}$ образуется сверхструктура $\mathrm{Nb}_{6} \mathrm{C}_{5}$ [12-14] и наблюдается сверхструктурный ближний порядок [15]. В качестве объекта исследования использовали крупнокристаллический и нанокристаллические порошки карбида $\mathrm{NbC}_{0.77}$.

\section{2. Образцы и экспериментальные методы}

Крупнокристаллический порошок карбида ниобия $\mathrm{NbC}_{0.77}$ со средним размером частиц $2-3 \mu \mathrm{m}$ был синтезирован высокотемпературным твердофазным вакуумным спеканием [16,17]. Нанокристаллические порошки $\mathrm{NbC}_{0.77}$ получили высокоэнергетическим размолом крупнокристаллического порошка в планетарной шаровой мельнице PM-200 Retsch в течение 5, 10 и $15 \mathrm{~h}$. Методика размола подробно описана в [4-6,18].

Предварительную структурную аттестацию порошков $\mathrm{NbC}_{0.77}$ проводили на рентгеновском дифрактометре Shimadzu XRD-7000 методом Брегга-Брентано в интервале углов $2 \theta$ от 10 до $140^{\circ}$ с пошаговым сканированием $\Delta(2 \theta)=0.03^{\circ}$ и временем экспозиции $2 s$ в точке в излучении $\mathrm{Cu} K \alpha_{1,2}$. Рентгенограммы численно анализировали с помощью программного пакета X'Pert HighScore Plus [19]. Функция разрешения дифрактометра Shimadzu XRD-7000 была определена в специальном дифракционном эксперименте на кубическом гексабориде лантана LaB6 (NIST Standart Reference Powder 660a).

Нейтронографические спектры высокого разрешения от всех образцов получены при температуре $293 \mathrm{~K}$ на TOF-дифрактометре высокого разрешения HRFD [20], действующем на канале № 5 импульсного реактора ИБР-2 (ОИЯИ, Дубна). В области межплоскостных 
расстояний $d_{h k l}$ от $\sim 0.1$ до $\sim 0.5 \mathrm{~nm}$ разрешающая способность $\Delta d / d$ этого дифрактометра составляет $\sim 0.001$ и почти не зависит от $d_{h k l}$. Для определения функции разрешения дифрактометра использовали стандартный образец $\mathrm{Al}_{2} \mathrm{O}_{3}$. В изученном интервале межплоскостных расстояний $0.05-0.50 \mathrm{~nm}$ ширину дифракционных пиков, $W_{R}$, связанную с функцией разрешения дифрактометра HRFD, можно аппроксимировать линейной зависимостью $W_{R}^{2}=\left(1.66+73.8 d^{2}\right) \cdot 10^{-8} \mathrm{~nm}^{2}$. Анализ нейтронограмм по методу Ритвельда выполняли с помощью программного пакета FullProf [21].

По данным рентгеновской дифракции исходный крупнокристаллический порошок $\mathrm{NbC}_{077}$ является однофазным, имеет кубическую (пр. гр. $F m \overline{3} m$ ) структуру типа $B 1$ с периодом кристаллической решетки $a=0.44373 \mathrm{~nm}$. О высокой степени гомогенности исходного карбида $\mathrm{NbC}_{0.77}$ свидетельствует расщепление $\mathrm{CuK \alpha} 1,2$-дублетов, которое наблюдается уже для линии (311). Оценка степени гомогенности $\Delta y$ исходного карбида, выполненная согласно [17] по рентгеновским данным, показала, что $\Delta y=0.01$, т.е. состав карбида определен с точностью $\mathrm{NbC}_{0.77 \pm 0.01}$. Следует отметить, что на нейтронограмме крупнокристаллического карбида $\mathrm{NbC}_{077}$ в узкой области слева от дифракционных отражений, т. е. в области меньших $d$, присутствуют слабые наплывы; на рентгенограмме крупнокристаллического $\mathrm{NbC}_{077}$, развернутой по углу дифракции $2 \theta$, тоже присутствуют слабые наплывы. Формально эту особенность дифракционных спектров крупнокристаллического $\mathrm{NbC}_{077}$ можно описать как наличие второй карбидной фракции с малым размером частиц. Более вероятно, что слабые наплывы обусловлены микронеоднородностями исходного карбида $\mathrm{NbC}_{077}$, незначительно (менее, чем разрешающая способность $\Delta d / d$ дифрактометра) различающимися величиной межплоскостных расстояний. Такое явление характерно для сильно нестехиометрических карбидов $[11,16]$, особенно в областях возможного образования сверхструктур.

Рентгеновская дифракция нанопорошков $\mathrm{NbC}_{0.77}$ обнаружила в них наряду с основной кубической фазой от 1.0 до $3.5 \mathrm{wt} . \%$ примесного гексагонального карбида вольфрама WC [22]. Появление WC обусловлено натиранием при размоле материала мелющих шаров и футеровки стаканов, изготовленных из твердого сплава WC 6 wt.\% Co. На нейтронограммах отражения от примеси $\mathrm{WC}$ неразличимы на фоне ошибок эксперимента из-за ее малого объема.

По данным рентгеновской дифракции уширение дифракционных отражений нанопорошков $\mathrm{NbC}_{0.77}$ обусловлено как малым размером $D$ областей когерентного рассеяния (ОКР), так и наличием микродеформаций $\varepsilon$. Дополнительно методом БЭТ на приборе Gemini VII 2390t Surface Area Analyzer измеряли удельную поверхность $S_{s p}$ исходного порошка $\mathrm{NbC}_{0.77}$ и полученных из него нанопорошков. В приближении одинакового размера и шарообразной формы всех частиц по величине удельной поверхности $S_{s p}$ оценивали средний размер
$D$ частиц. В пределах ошибок измерений этот размер $D$ согласуется с размером ОКР, найденным рентгенодифракционным методом.

\section{3. Обсуждение результатов}

Количественный анализ данных нейтронной дифракции нанопорошков $\mathrm{NbC}_{0.77}$ показал, что профили дифракционных отражений наилучшим образом описываются при учете двух фракций нанопорошка с разным периодом решетки, разным составом и разным средним размером частиц. Как пример на рис. 1 показан профиль пика (200) нанопорошка, полученного размолом в течение $5 \mathrm{~h}$. Полное отражение является суммой двух пиков: узкого и широкого. Основной вклад (> 92\%) в отражение вносит широкий пик, соответствующий наноразмерной фракции $F_{1}$ и смещенный в область меньших $d$ относительно узкого пика. Такая же особенность наблюдается для всех отражений на нейтронограммах нанопорошков. Таким образом, в нанопорошках карбида ниобия одновременно сосуществуют две кубические фракции $F_{1}$ и $F_{2}$, отличающиеся периодом $a_{B 1}$ решетки и размером частиц.

Нейтронограммы исходного крупнокристаллического порошка $\mathrm{NbC}_{0.77}$ и нанопорошков $\mathrm{NbC}_{0.77}$, измеренные на TOF-дифрактометре, показаны на рис. 2. Дифракционные отражения нанопорошков сильно уширены вследствие размола; кроме того, наблюдается увеличение диффузного фона.

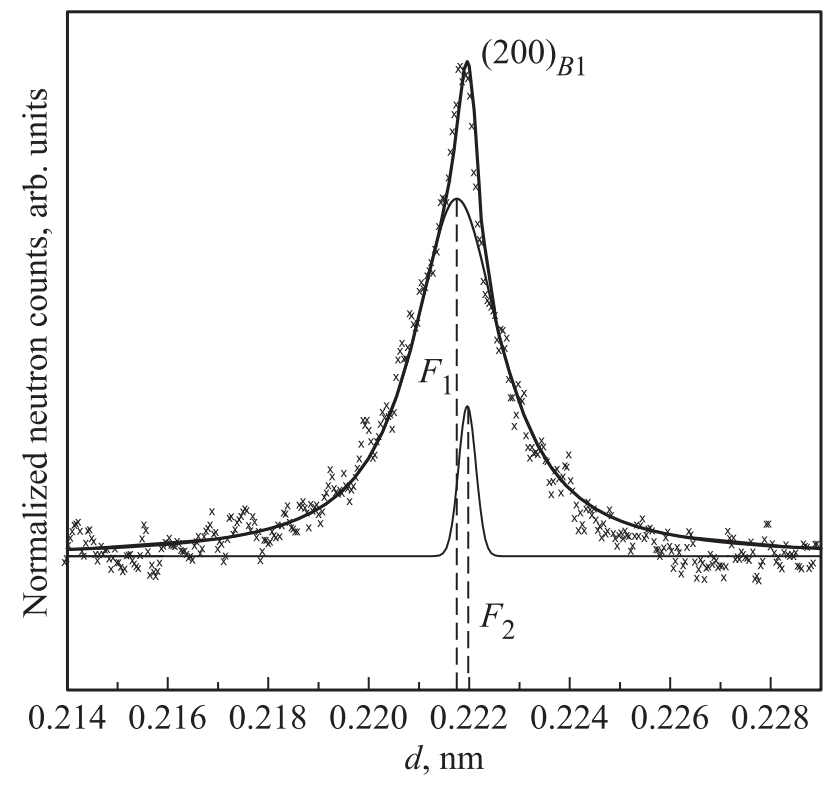

Рис. 1. Дифракционное отражение (200) нанопорошка, полученного размолом в течение $5 \mathrm{~h}$, и его разложение в двухфазной модели на пики, соответствующие кубическим фракциям $F_{1}$ и $F_{2}$ карбида ниобия с разным периодом решетки, разным составом и разным средним размером частиц. Показаны экспериментальные точки и расчетные кривые. 


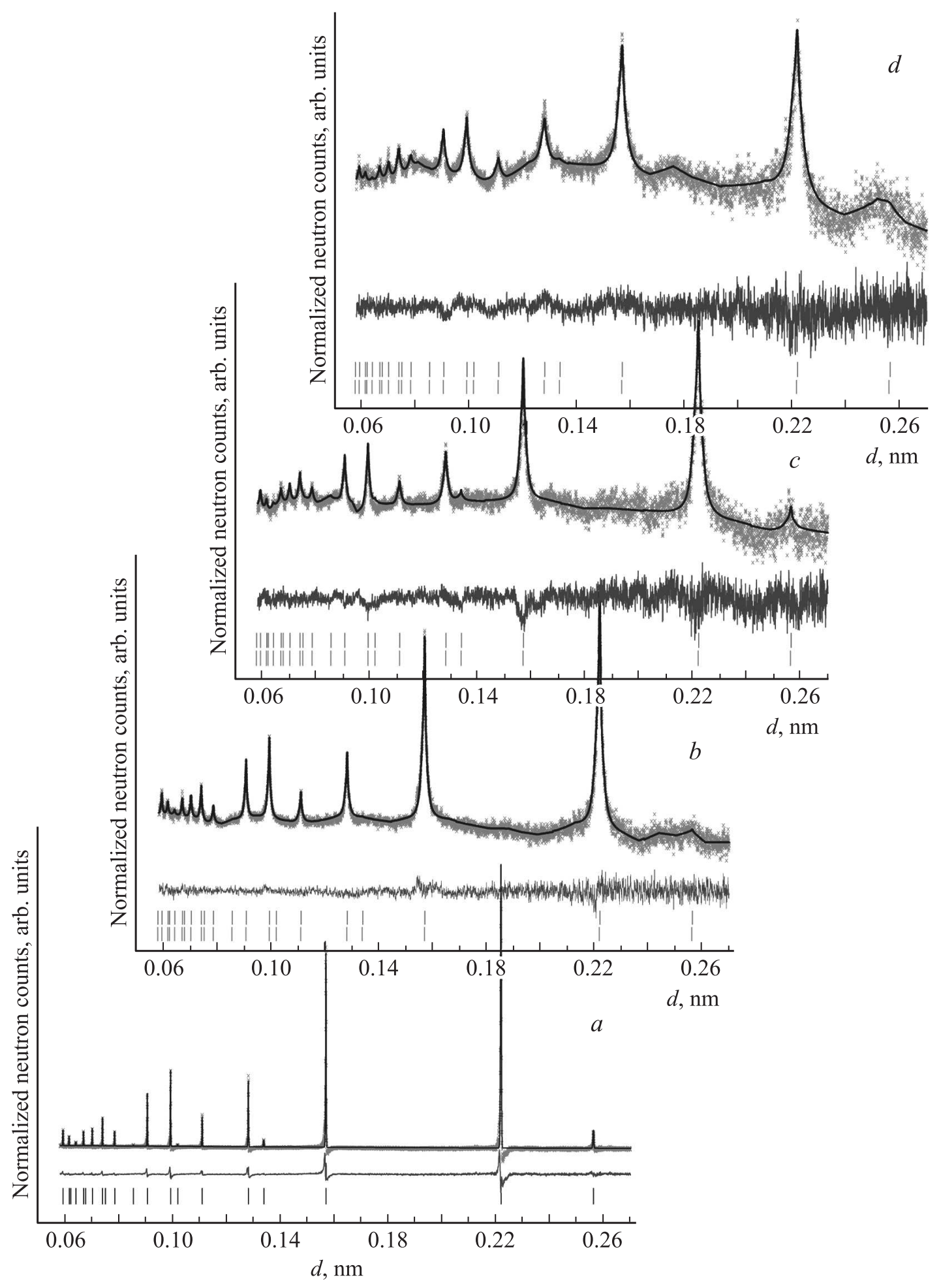

Pис. 2. Измеренные на HRFD нейтронограммы $(a)$ исходного крупнокристаллического порошка $\mathrm{NbC}_{0.77}$ и нанокристаллических порошков $\mathrm{NbC}_{0.77}$, полученных из него размолом в течение $(b) 5,(c) 10$ и $(d) 15 \mathrm{~h}$. Показаны экспериментальные точки, расчетная кривая и разностная функция (в нижней части рисунков). Нижний и верхний ряды вертикальных штрихов на нейтронограммах нанопорошков соответствуют расчетным положениям дифракционных пиков нанокристаллической $F_{1}$ и крупнокристаллической $F_{2}$ фракций соответственно. 
Влияние продолжительности $t$ размола на величину удельной поверхности $S_{s p}$, размер $D$ областей когерентного рассеяния и среднюю величину микродеформаций $\varepsilon_{\text {aver }}$ в нанокристаллической фракции $F_{1}$ нанопорошков нестехиометрического карбида ниобия $\mathrm{NbC}_{0.77}$

\begin{tabular}{r|c|c|c|c|c|c|c|c}
\hline \multirow{2}{*}{$t,(\mathrm{~h})$} & \multirow{2}{*}{$a_{B 1}(\mathrm{~nm})$} & $S_{s p} \pm 0.20\left(\mathrm{~m}^{2} \mathrm{~g}^{-1}\right)$ & \multicolumn{4}{|c|}{$D(\mathrm{~nm})$} & \multicolumn{2}{c}{$\varepsilon_{\text {aver }}(\%)$} \\
\cline { 3 - 8 } & & & БЭТ & рентген & нейтроны & расчет $[24]$ & рентген & нейтроны \\
\hline 0 & 0.44373 & 0.282 & $2730 \pm 50$ & - & - & - & - & - \\
5 & 0.44352 & 13.77 & $56 \pm 3$ & $48 \pm 5$ & $35 \pm 11$ & 40 & $0.43 \pm 0.03$ & $0.27 \pm 0.03$ \\
10 & 0.44350 & 19.35 & $40 \pm 3$ & $41 \pm 5$ & $17 \pm 3$ & 26 & $0.71 \pm 0.04$ & $0.47 \pm 0.05$ \\
15 & 0.44351 & 24.44 & $32 \pm 3$ & $23 \pm 5$ & $16 \pm 2$ & 20 & $0.70 \pm 0.04$ & $0.62 \pm 0.06$
\end{tabular}

С учетом ошибок эксперимента из анализа нейтронограмм следует, что во всех нанопорошках периоды решетки основной (нанокристаллической) фракции $F_{1}$ и второй фракции $F_{2}$ равны $\sim 0.4433$ и $\sim 0.4439 \mathrm{~nm}$, а содержание основной фракции $F_{1}$ в нанопорошках, полученных размолом в течение 5,10 и $15 \mathrm{~h}$, составляет $\sim 92, \sim 94$ и $\sim 98 \%$ соответственно. Судя по уширению, основная фракция является нанокристаллической с размером ОКР $\sim 35, \sim 17$ и $\sim 16 \mathrm{~nm}$ (таблица). С увеличением продолжительности размола содержание нанокристаллической фракции $F_{1}$ растет, а крупнокристаллической фракции $F_{2}$ становится меньше. Из зависимости периода решетки $\mathrm{NbC}_{y}$ от относительного содержания углерода $y[16,23]$ следует, что нано- и крупнокристаллическая фракции имеют состав $\sim \mathrm{NbC}_{0.76}$ и $\sim \mathrm{NbC}_{0.79}$.

Микронеоднородное строение нанопорошков $\mathrm{NbC}_{0.77}$ подтверждается данными электронной просвечивающей микроскопии высокого разрешения (HRTEM). На рис. 3 как пример показано HRTEM изображение частицы нанопорошка, полученного 5-часовым размолом. Имеются отдельные участки, которые отличаются взаимной ориентацией, наблюдаемой системой межплоскостных расстояний и, что наиболее существенно, величинами периода решетки, которые можно соотнести с фракциями $F_{1}$ и $F_{2}$. Аналогичные результаты по микронеоднородному строению были получены ранее для нанопо-

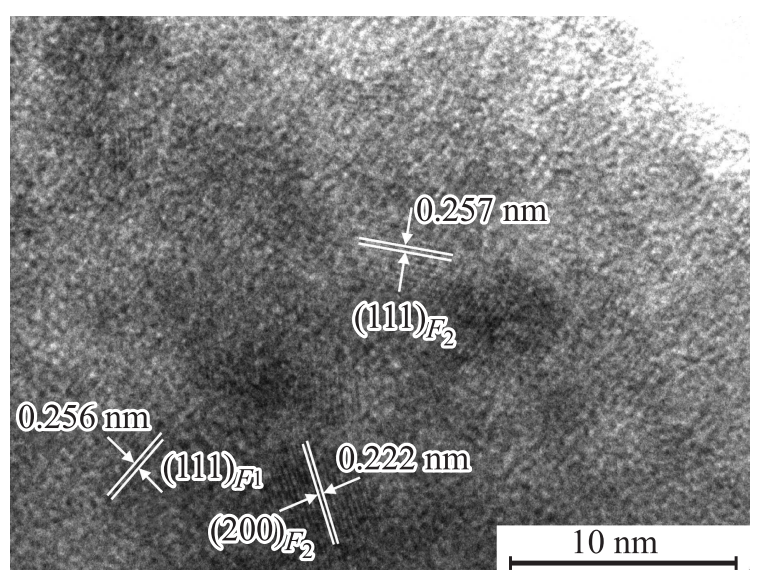

Рис. 3. НRTEM изображение неоднородностей частицы нанопорошка $\mathrm{NbC}_{0.77}$, полученного размолом в течение $5 \mathrm{~h}$. рошков $\mathrm{PbS}$ [24] и $\mathrm{Ag} 2 \mathrm{~S}$ [25], в которых тоже возможно проявление нестехиометрии, но гораздо меньше, чем в кубических карбидах.

Зависимость ширины $\Delta d$ дифракционных отражений от межплоскостного расстояния $d$ поликристалла при измерении на TOF-дифрактометре HRFD описывается [10] как

$$
(\Delta d)^{2}=c_{1}+c_{2} d^{2}+c_{3} d^{2}+c_{4} d^{4},
$$

где коэффициенты $c_{1}$ и $c_{2}$ связаны с функцией разрешения и параметрами дифрактометра (пролетное расстояние, угол рассеяния), $c_{3} \approx(2 \varepsilon)^{2}, c_{4} \approx(k / D)^{2}, \varepsilon-$ микродеформация, $D$ - характерный размер ОКР (или, в первом приближении, размер частицы). При отсутствии эффекта малого размера зависимость (1) как функция от $d^{2}$ будет линейной, а при малом размере частиц параболической и вогнутой.

Наиболее известными причинами уширения дифракционных отражений являются малый размер $D$ частиц (кристаллитов) и микронапряжения $\varepsilon$ кристаллической решетки, обусловленные ее деформационными искажениями и смещениями атомов из-за наличия дислокаций. Согласно [26], для описания экспериментальных данных необходимо учесть в уравнении (1) дополнительный коэффициент, отвечающий за анизотропию микродеформаций.

В работе [8] показано, что уширение $\beta_{d}(2 \theta)$, обусловленное деформационными искажениями кристаллической решетки, связано с анизотропией этих искажений и равно

$$
\begin{aligned}
\beta_{d}(2 \theta) & =4 \varepsilon_{h k l} \operatorname{tg} \theta \equiv 4 k_{p} c_{h k l}^{1 / 2} \operatorname{tg} \theta \\
& \equiv 4 k_{p}(A+B H)^{1 / 2} \operatorname{tg} \theta,
\end{aligned}
$$

где $\varepsilon_{h k l}=k_{p} c_{h k l}^{1 / 2}$ - эффективная микродеформация, связанная с анизотропным модулем Юнга $E_{h k l}$ кристалла и учитывающая анизотропию деформации кристалла; $k_{p}$ - постоянная для данного образца величина, зависящая от плотности дислокаций и вектора Бюргерса; $c_{h k l}=A+B H-$ коэффициент, учитывающий наличие краевых и винтовых дислокаций; $A$ и $B-$ постоянные для данного образца величины, зависящие от плотности дислокаций и их относительного содержания; 
$H=\left(h^{2} k^{2}+k^{2} l^{2}+h^{2} l^{2}\right) /\left(h^{2}+k^{2}+l^{2}\right)-$ дислокационный фактор анизотропии для кубических кристаллов. С учетом (2) выражение (1) приобретает вид

$$
(\Delta d)^{2}=c_{1}+c_{2} d^{2}+c_{3}(A+B H) d^{2}+c_{4} c^{4} .
$$

Экспериментальное уширение связано с величиной $\Delta d$ как $W=K \Delta d$, где для дифрактометра HRFD константа $K=25912.7$, если $\Delta d$ измеряется в $\mathrm{nm}$. Заменяя в (3) $\Delta d$ на $W$, получим

$$
W^{2}=C_{1}+C_{2} d^{2}+C_{3}(A+B H) d^{2}+C_{4} d^{4},
$$

где $C_{i}=c_{i} K^{2}, C_{1}+C_{2} d^{2}=W_{R}^{2}-$ квадрат функции разрешения $W_{R}$ дифрактометра, а третье и четвертое слагаемые представляют вклады деформационного и размерного уширения. С учетом функции разрешения экспериментальное уширение произвольного отражения $(h k l)$ имеет вид

$$
W_{h k l}^{2}=C_{3}(A+B H) d_{h k l}^{2}+C_{4} d_{h k l}^{4} .
$$

Если анизотропия деформационных искажений отсутствует или пренебрежимо мала, то выражение (5) приобретает обычный вид

$$
W_{h k l}^{2}=C_{3} d_{h k l}^{2}+C_{4} d_{h k l}^{4}
$$

Легко видеть, что при отсутствии деформационных искажений зависимость $W_{h k l}^{2}$ от $d_{h k l}^{2}$ будет линейной, а при наличии изотропных деформационных искажений будет параболической и вогнутой, так как по определению $C_{3}=(2 \varepsilon)^{2} \geq 0$ и $C_{4}=\left(1 / D^{2}\right) \geq 0$.

Экспериментальные зависимости $W^{2}\left(d^{2}\right)$, определенные для порошков $\mathrm{NbC}_{0.77}$ из спектров HRFD, показаны на рис. $4(1)$. Зависимость $W^{2}\left(d^{2}\right)$ для крупнокристаллического порошка является линейной, а зависимости $W^{2}\left(d^{2}\right)$ для фракции $F_{1}$ нанопорошков, полученных размолом в течение 5,10 и $15 \mathrm{~h}$, являются выпуклыми. Выпуклые зависимости $W^{2}\left(d^{2}\right)$ нельзя описать функцией (6) с положительными коэффициентами $C_{3}$ и $C_{4}$. Эти зависимости хорошо описываются функцией (5) с поправкой на фактор анизотропии $H$

$$
W_{H}^{2}=W_{h k l}^{2}-C_{3} B H d_{h k l}^{2}=C_{3} A d_{h k l}^{2}+C_{4} d_{h k l}^{4} .
$$

Действительно, аппроксимация тех же самых экспериментальных данных по $W^{2}\left(d^{2}\right)$ для порошков $\mathrm{NbC}_{0.77}$ зависимостью (7) с учетом анизотропии микродеформаций дает хорошее описание эксперимента (рис. 4(2)) и позволяет определить деформации $\varepsilon_{h k l}$ и размер $D$ ОКР. Среднее значение микродеформаций $\varepsilon_{\text {aver }}$ в соответствии с [8] находили как $\varepsilon_{\text {aver }}=\left(\Sigma \varepsilon_{h k l} P_{h k l}\right) / \Sigma P_{h k l}$, т. е. усреднением микродеформаций $\varepsilon_{h k l}$ с учетом фактора повторяемости $P_{h k l}$.

Результаты по $D$ и $\varepsilon_{\text {aver }}$, найденные из нейтронографических измерений, неплохо согласуются с аналогичными данными, полученными рентгеновской дифракцией, с величиной $D$, оцененной по удельной поверхности
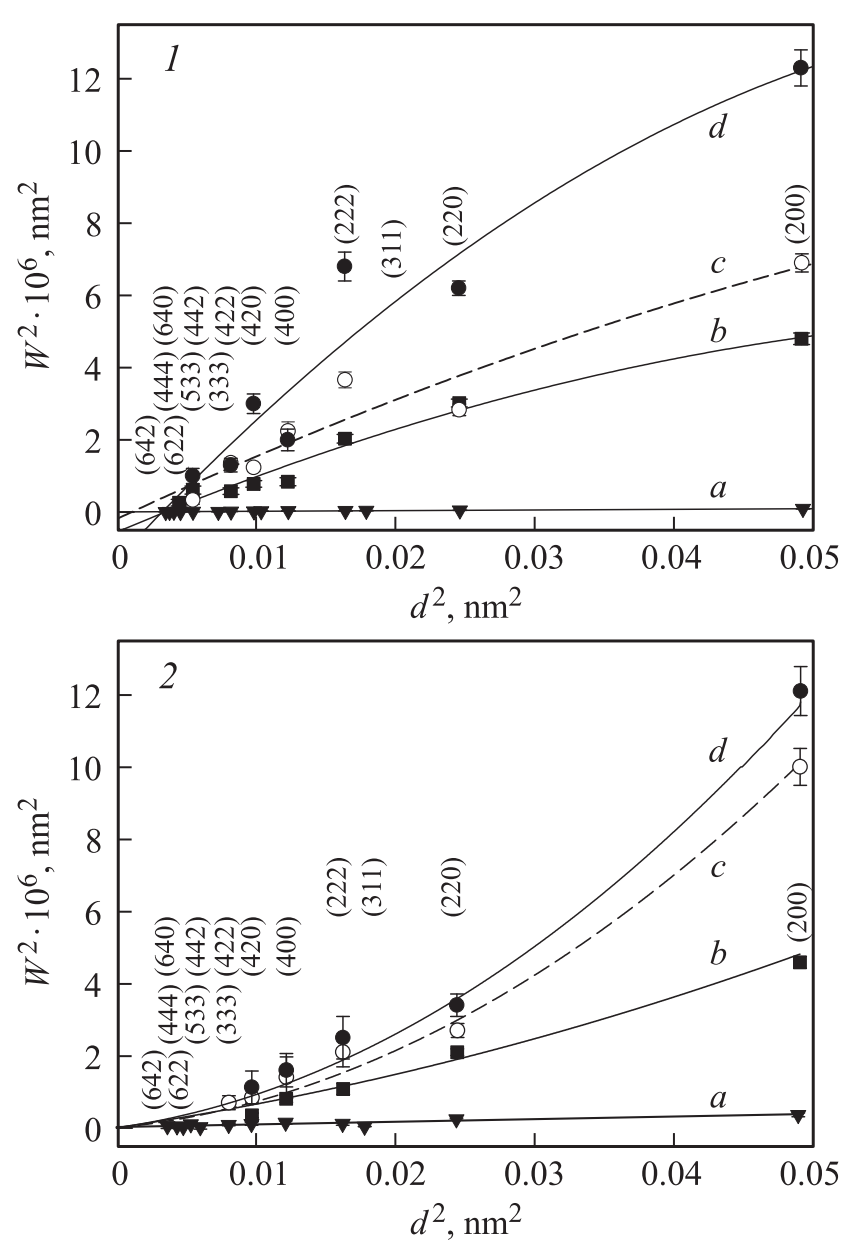

Рис. 4. Экспериментальные зависимости (1) $W^{2}\left(d^{2}\right)$ и (2) $W_{H}^{2}\left(d^{2}\right)$ порошков карбида ниобия $\mathrm{NbC}_{0.77}:(a)$ крупнокристаллический, $(b),(c)$ и $(d)$ нанопорошки, полученных размолом в течение 5,10 и $15 \mathrm{~h}$ соответственно. Указаны индексы $(h k l)$ дифракционных отражений.

нанопорошков, а также с теоретически рассчитанным в работе [27] размером частиц нанопорошков (таблица).

Проведенное исследование показало, что нанопорошки $\mathrm{NbC}_{0.77}$ имеют не вполне однородный фракционный состав и содержат две кубические фракции с разным размером частиц, т.е. обладают бимодальным размерным распределением. Стандартные дифракционные методы не позволяют определить детали такого распределения, но их удалось выяснить при совместном анализе профиля всех дифракционных отражений нанопорошков карбида ниобия, измеренных на нейтронном дифрактометре HRFD. Анализ нейтронографических данных обнаружил в нанопорошках анизотропию микродеформаций.

В целом исследование нанопорошков нестехиометрического карбида ниобия $\mathrm{NbC}_{0.77}$ показало перспективность TOF-дифрактометрии для изучения сильно деформированных нестехиометрических соединений.

Исследование поддержано проектом РФФИ № 14-29-04091 офи_м. 


\section{Список литературы}

[1] А.И. Гусев. УФН 168, 1, 55 (1998). [A.I. Gusev. Phys. Uspekhi 41, 1, 49 (1998)].

[2] A.I. Gusev, A.A. Rempel. Nanocryst. Mater. Cambridge Intern. Science Publ., Cambridge (2004). 351 pp.

[3] А.И. Гусев. Наноматериалы, наноструктуры, нанотехнологии. 3-е изд. Физматлит, М. (2009). 416 с.

[4] A.I. Gusev, A.S. Kurlov. Nanotechnology 19, 26, 265302 (2008).

[5] A.S. Kurlov, A.I. Gusev. Techn. Phys. 56, 7, 975 (2011).

[6] A.S. Kurlov, A.I. Gusev. Tungsten Carbides: Structure, Properties and Application in Hardmetals. Springer, ChamHeidelberg-N.Y.-Dordrecht-London (2013). 256 p.

[7] S.I. Sadovnikov, A.I. Gusev, A.A. Rempel. Rus. Chem. Rev. 85, 7, 731 (2016).

[8] А.С. Курлов, И.А. Бобриков, А.М. Балагуров, А.И. Гусев. Письма в ЖЭТФ 100, 10, 712 (2014). [A.S. Kurlov, I.A. Bobrikov, A.M. Balagurov, A.I. Gusev. JETP Lett. 100, 10, 629 (2014)].

[9] А.И. Гусев, А.С. Курлов, И.А. Бобриков, А.М. Балагуров. Письма в ЖЭТФ 102, 3, 179 (2015). [A.I. Gusev, A.S. Kurlov, I.A. Bobrikov, A.M. Balagurov. JETP Lett. 102, 3, 154 (2015)].

[10] A.M. Balagurov, I.A. Bobrikov, G.D. Bokuchava, R.N. Vasin, A.I. Gusev, A.S. Kurlov, M. Leon. Mater. Charact. 109, 173 (2015).

[11] A.S. Kurlov, A.I. Gusev, E.Yu. Gerasimov, I.A. Bobrikov, A.M. Balagurov, A.A. Rempel. Superlatt. Microstr. 90, 148 (2016).

[12] А.А. Ремпель, А.И. Гусев, В.Г. Зубков, Г.П. Швейкин. Докл. AH CCCP 275, 4, 883 (1984). [A.A. Rempel, A.I. Gusev, V.G. Zubkov, G.P. Shveikin. Sov. Phys. Dokl. 29, 4, 257 (1984)].

[13] A.I. Gusev, A.A. Rempel. Phys. Statis Solidi B 140, 2, 335 (1987).

[14] A.I. Gusev, A.A. Rempel. J. Phys. Chem. Sol. 55, 3, 299 (1994).

[15] A.A. Rempel, A.I. Gusev. Phys. Status Solidi B 160, 2, 389 (1990).

[16] A.I. Gusev, A.A. Rempel, A.J. Magerl. Disorder and Order in Strongly Nonstoichiometric Compounds: Transition Metal Carbides, Nitrides and Oxides. Springer, BerlinHeidelberg-N.Y.-London (2001). 607 p.

[17] А.А. Ремпель, А.И. Гусев. ФТТ 42, 7, 1243 (200). [A.A. Rempel, A.I. Gusev. Phys. Solidi State 42, 7, 1280 (2000)].

[18] A.S. Kurlov, A.I. Gusev. J. Alloys Comp. 582, 108 (2014).

[19] X'Pert HighScore Plus. Version 2.2e (2.2.5). (C) 2009 PANalytical B.V. Almedo, the Netherlands.

[20] A.M. Balagurov. Neutron News 16, 3, 8 (2005).

[21] J. Rodríguez-Carvajal. Physica B 192, 1-2, 55 (1993).

[22] A.A. Rempel, R. Würschum, H.-E. Schaefer. Phys. Rev. B 61, 9, 5945 (2000).

[23] V.N. Lipatnikov, A.A. Rempel, A.I. Gusev. Inorg. Mater. 26, 12, 2171 (1990).

[24] S.I. Sadovnikov, N.S. Kozhevnikova, V.G. Pushin, A.A. Rempel. Inorg. Mater. 48, 1, 21 (2012).

[25] S.I. Sadovnikov, A.A. Rempel. Inorg. Mater. 51, 8, 759 (2015).

[26] M. Leoni, J. Martinez-Garcia, P. Scardi. J. Appl. Crystallogr. 40, 4, 719 (2007).

[27] A.S. Kurlov, A.I. Gusev. Inorg. Mater. 51, 1, 29 (2015). 